\title{
Serum levels of IGFBP7 are elevated during acute exacerbation in COPD patients
}

\author{
This article was published in the following Dove Press journal: \\ International Journal of COPD \\ 19 June 2017 \\ Number of times this article has been viewed
}

\author{
Wenjing Ruan' \\ Minliang $\mathrm{Wu}^{2}$ \\ Liuhong Shi ${ }^{1}$ \\ Fengying $\mathrm{Li}^{3}$ \\ Liangliang Dong' \\ Yuanhua Qiu' \\ Xiaohong $\mathrm{Wu}^{\prime}$ \\ Kejing Ying'
}

'Department of Respiratory Diseases, Sir Run Run Shaw Hospital, School of Medicine, Zhejiang University,

${ }^{2}$ Department of Laboratory, The Second Affiliated Hospital of Zhejiang University, School of Medicine,

${ }^{3}$ Department of Laboratory, Sir Run Run Shaw Hospital, School of Medicine, Hangzhou, China
Correspondence: Kejing Ying Department of Respiratory Diseases, Sir Run Run Shaw Hospital, School of Medicine, Qingchun East Road 3\#, 310016 Zhejiang University, Hangzhou, China

Email rwj@zju.edu.cn
Objective: The purpose of this study was to explore the insulin-like growth factor binding protein 7 (IGFBP7) level in the serum of chronic obstructive pulmonary disease (COPD) patients during acute exacerbation (AE).

Methods: The study population consisted of 47 AECOPD patients, including 25 patients enrolled between January 2011 and February 2011 (the first group) and 22 patients enrolled from December 2011 to August 2012 (the second group) and 29 healthy controls. Chemiluminescencelinked immunoassay was used to detect serum IGFBP7 levels. For the second group patients, IGFBP7 and C-reactive protein (CRP) levels were measured both on the admission day and on the discharge day.

Results: Among the first group AECOPD patients, serum IGFBP7 levels were significantly elevated in AECOPD patients in the intensive care unit (ICU; $52.92 \pm 16.32 \mathrm{ng} / \mathrm{mL}$ ), and in hospitalized AECOPD patients not in ICU (40.66 13.9$)$, compared to healthy subjects $(30.3 \pm 7.09 \mathrm{ng} / \mathrm{mL} ; P<0.01)$. For the second group AECOPD patients, the increased IGFBP7 levels reduced after the patients had recovered $(34.42 \pm 11.88$ vs $27.24 \pm 7.2 \mathrm{ng} / \mathrm{mL} ; P<0.01)$. During AE, the correlation coefficient between IGFBP7 and CRP was 0.357. In receiver operating characteristic analysis, the area under the curve was 0.799 for CRP, and 0.663 for IGFBP7 in distinguishing patients with AECOPD on the admission day from the discharge day.

Conclusion: Serum IGFBP7 levels were raised during AECOPD. Similar to the expression pattern of CRP, the IGFBP7 levels reduced after convalescence, suggesting that IGFBP7 might have a candidate role as a biomarker of AECOPD. No significant linear correlation was detected between IGFBP7 and CRP, indicating the probable different role for the two molecules in assessing AECOPD. Further study is needed to explore the value of IGFBP7 in differentiating phenotypes of AECOPD.

Keywords: acute exacerbation, biomarker, COPD, IGFBP7, serum

\section{Introduction}

Acute exacerbation of chronic obstructive pulmonary disease (AECOPD) results in emergency room visits and hospitalizations, which are responsible for most mortality in COPD patients. ${ }^{1}$ The diagnosis of AE depends on the acute change in the patient's symptoms, including productive cough and dyspnea. ${ }^{2,3}$ Multiple growth factors are upregulated during airway inflammation, promoting COPD pathogenesis by causing airway remodeling and disrupting interstitial tissue and alveolar integrity, leading to airway narrowing, parenchymal damage, emphysema, and impaired lung function. ${ }^{4}$ The systemic low-grade inflammation in stable COPD increases during AE. ${ }^{5,6}$ Identification of serum biomarkers could help clinicians to better manage and prevent exacerbations. Biomarkers may fluctuate in accordance with disease state, which may provide important clues to the potential signaling pathways of the disease. ${ }^{7}$ 
The insulin-like growth factor binding protein (IGFBP) family serves as a group of carrier proteins for insulin-like growth factor-1 (IGF-1). Recently, the role of an IGFBP family member, like IGFBP3, has been reported to function in airway inflammation. ${ }^{8}$ Among the IGFBP superfamily members, the binding affinity of IGFBP7 to IGFs was lower than conventional IGFBP1-6. On the contrary, the protein had high binding affinity to insulin. ${ }^{9}$ In recent years, the functional role of IGFBP7 has been explored. The protein is associated with cell growth, senescence, and cell adhesion. ${ }^{10}$ IGFBP7 was found in unfractionated bronchoalveolar lavage cells (BALC) and in activated human alveolar macrophage precursor peripheral blood monocytes, suggesting the expression pattern of IGFBP7 in normal human airway and alveoli. ${ }^{11}$ Muller et al reported an increased expression of senescenceassociated IGFBP7 in fibroblasts from emphysema patients. ${ }^{12}$ Airway inflammation is the key character of the human chronic airway diseases. ${ }^{13}$ The intriguing possibility of involvement of IGFBP7 in AECOPD merits further investigation. This study aimed to investigate the expression level of IGFBP7 in hospitalized COPD patients during AE.

\section{Materials and methods Study population}

The diagnosis of COPD referred to the Global Initiative for Chronic Obstructive Lung Disease (GOLD) guidelines. Exacerbations were defined according to the GOLD criteria. Selected COPD patients were excluded if they were diagnosed with active pulmonary tuberculosis, cancer, interstitial lung disease, or clinically significant bronchiectasis. The study population consisted of 47 AECOPD patients. Two independent AECOPD patient groups were included in the study. From January 2011 to February 2011, 25 hospitalized AECOPD patients were enrolled (the first group); among them 11 patients were admitted in intensive care unit (ICU) requiring assisted ventilation owing to severe acute exacerbations. From December 2011 to August 2012, 22 hospitalized AECOPD patients were enrolled (the second group). Twenty-nine age-matched healthy subjects were included in the study. Healthy controls were selected from the population on the basis of routine physical examination. All patients gave written informed consent. The research started after agreement from the Medical Ethics Committee of the Sir Run Run Shaw Hospital.

\section{Study design}

A venous blood sample was obtained from each hospitalized AECOPD patient on admission day. Serum IGFBP7 was measured. Arterial blood gases were measured at the same time. For the analysis of the arterial blood gases, the delay between sampling and measurement was $<30$ minutes. Age, sex, smoking history, and length of hospital stay were recorded.

Owing to a different research goal, for the second group of patients, a sample for the analysis of white blood cell count (WBC), neutrophil count, C-reactive protein (CRP), and procalcitonin (PCT) was obtained at the same time. To detect IGFBP7 and CRP levels in COPD patients who had recovered from AE, follow-up venous blood samples were obtained on the discharge day in the second group of patients. The decisions to discharge were based on the GOLD guidelines. ${ }^{14}$

\section{Blood sampling}

Volume conductivity scatter technology was applied for WBC and differential counts (Coutlet hematology analyzer LH780; Beckman Coulter Inc, Brea, CA, USA). For biochemical measurements, the supernatants were stored at $-70^{\circ} \mathrm{C}$ after centrifugation at room temperature at $2,000 \times g$. The separated serum sample was aliquoted into sterile microcentrifuge tubes (500 $\mu \mathrm{L}$ each vial), then stored at $-80^{\circ} \mathrm{C}$.

\section{Biochemical measurements}

Polyclonal and monoclonal anti-IGFBP7 antibody was purchased from R\&D Systems Inc. (Abingdon, UK). Chemiluminescence-linked immunoassay was used to detect serum IGFBP7 levels. ${ }^{15}$ Enzyme-linked fluorescent assay (ELFA) was used to detect CRP and PCT levels (BioMerieux Vidas, Lyon, France).

\section{Statistical analyses}

Quantitative data were expressed as means \pm standard deviations (SD). Chi-square test was used to compare the baseline clinical characteristics of the patients. One-way analysis of variance was used to detect the differences between subject groups. $P$-values $<0.05$ were considered statistically significant.

Spearman correlation analysis was performed to find the correlations between IGFBP7 and CRP levels in the patients suffering from AE. All statistical analyses were performed using SPSS for Windows, version 20.0 (IBM Corporation, Armonk, NY, USA).

\section{Results}

\section{Characteristics of subjects}

The baseline characteristics of the 25 AECOPD patients of the first group and healthy control subjects are summarized in Table 1. To verify the biomarker candidates, an independent 
Table I Baseline characteristics of the subjects of the first group

\begin{tabular}{|c|c|c|c|c|}
\hline & $\begin{array}{l}\text { AECOPD in } \\
\text { ICU }(n=I I)\end{array}$ & $\begin{array}{l}\text { AECOPD } \\
\text { not in ICU } \\
(n=14)\end{array}$ & $\begin{array}{l}\text { Healthy } \\
\text { control } \\
(n=29)\end{array}$ & $P$-value \\
\hline $\begin{array}{l}\text { Age (years) } \\
\text { mean } \pm \text { SD }\end{array}$ & $77.64 \pm 8.52$ & $78.36 \pm 3.95$ & $75 \pm 5.8$ & 0.623 \\
\hline Men:women & $7: 4$ & $11: 3$ & $21: 8$ & 0.585 \\
\hline Ever-smoker (n, \%) & $8(73)$ & II (79) & $21(73)$ & 0.564 \\
\hline $\begin{array}{l}\mathrm{PaCO}_{2}(\mathrm{mmHg}) \\
\text { mean } \pm \mathrm{SD}\end{array}$ & $80.09 \pm 8.42$ & $55.93 \pm 7.1$ & NA & NA \\
\hline Hospital stay & NA & $13.5 \pm 10.0$ & NA & NA \\
\hline $\begin{array}{l}\text { IGFBP7 }(\mathrm{ng} / \mathrm{mL}) \\
\text { mean } \pm \text { SD }\end{array}$ & $52.92 \pm 16.32$ & $40.66 \pm 13.90$ & $30.03 \pm 7.09$ & $P<0.0$ I \\
\hline
\end{tabular}

Abbreviations: AECOPD, acute exacerbation of chronic obstructive pulmonary disease; ICU, intensive care unit; IGFBP7, insulin-like growth factor binding protein 7; NA, not applicable.

panel of 22 hospitalized AECOPD subjects was used for the second group (Table 2).

\section{Serum IGFBP7 increased in AECOPD patients in the first group}

We first detected IGFBP7 levels in AECOPD patients in the first group. Among the 25 AECOPD patients, 11 were admitted to the ICU. IGFBP7 level in the ICU group, nonICU group, and healthy control group were $52.92 \pm 16.32$, $40.66 \pm 13.9$, and $30.3 \pm 7.09 \mathrm{ng} / \mathrm{mL}$, respectively. The increase in IGFBP7 compared with the healthy control group was significant $(P<0.01$; Figure 1). The level of IGFBP7 in AECOPD patients in ICU was higher than the other AECOPD patients, but not significant $(P>0.05)$.

\section{The increased IGFBP7 levels reduced after clinical recovery in the second group}

To reduce the potential bias, we verified the results in another population of 22 hospitalized AECOPD patients (the second

Table 2 Characteristics of the AECOPD subjects in the second group

\begin{tabular}{|c|c|}
\hline$n$ & 22 \\
\hline Age (years) & $74.3 \pm 7.75$ \\
\hline Sex (male:female) & $18: 4$ \\
\hline Ever-smoker, $\mathrm{n}$ & 16 \\
\hline CRP (mg/L) & $42.6 \pm 43.27$ \\
\hline PCT $(\mu \mathrm{g} / \mathrm{L})$ & $0.47 \pm 1.19$ \\
\hline WBC $\left(10^{9} / L\right)$ & $6.68 \pm 2.59$ \\
\hline$N\left(10^{9} / L\right)$ & $5.16 \pm 2.66$ \\
\hline $\mathrm{PaO}_{2} / \mathrm{FiO}_{2}$ & $236.68 \pm 65.97$ \\
\hline $\mathrm{PaCO}_{2}(\mathrm{mmHg})$ & $50.6 \mathrm{I} \pm 14.53$ \\
\hline Hospital stay (days) & $8.91 \pm 4.99$ \\
\hline IGFBP7 (ng/mL) & $34.42 \pm 11.88$ \\
\hline
\end{tabular}

Note: Data shown as mean \pm SD unless otherwise indicated.

Abbreviations: AECOPD, acute exacerbation of chronic obstructive pulmonary disease; CRP, C-reactive protein; PCT, procalcitonin; WBC, white blood cell count; $\mathrm{N}$, neutrophil\%; IGFBP7, insulin-like growth factor binding protein 7.

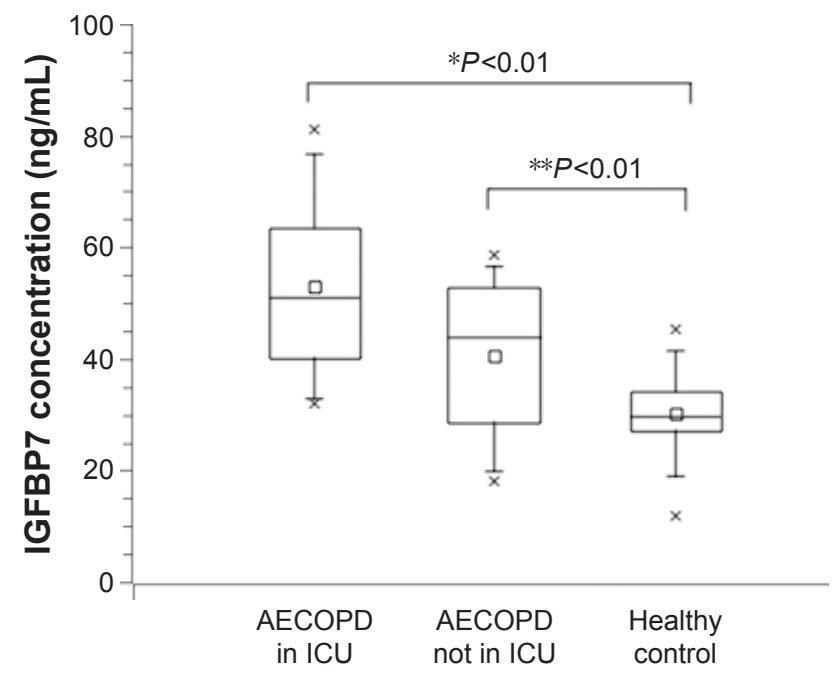

Figure I Serum IGFBP7 concentrations in patients with AECOPD in ICU, not in $I C U$, and healthy control subjects in the first group.

Abbreviations: AECOPD, acute exacerbation of chronic obstructive pulmonary disease; IGFBP7, insulin-like growth factor binding protein 7; ICU, intensive care unit.

group). The blood samples were obtained both on the admission day of $\mathrm{AE}$ and on the discharge day after recovery. Because of hemolysis during processing on the discharge day in two patients, a total of 20 follow-up samples were obtained. Serum IGFBP7 and CRP levels were both measured. We found that the increased serum IGFBP7 and CRP levels reduced after clinical recovery (IGFBP7: $34.42 \pm 11.88$ vs $27.24 \pm 7.20 \mathrm{ng} / \mathrm{mL}$; CRP: $42.6 \pm 43.27$ vs $6.61 \pm 6.62 \mathrm{ng} / \mathrm{mL}$ ) $(P<0.01$; Figure 2).

\section{No significant linear correlation existed between IGFBP7 and CRP during AE}

Both IGFBP7 and CRP levels increased during AE and reduced again after clinical recovery. To assess the correlation between IGFBP7 and CRP, Spearman correlation analysis was performed. However, unexpectedly, the correlation analysis between IGFBP7 and CRP showed no significant linear correlation between IGFBP7 and CRP during AE (Figure 3, $r=0.357, P=0.123$ ).

\section{Distinguishing power of IGFBP7 and CRP in patients with AECOPD}

The area under the curve in receiver operating characteristic (ROC) analysis was 0.799 for CRP and 0.663 for IGFBP7 in distinguishing patients with AECOPD on the admission day from the discharge day (Figure 4).

\section{Discussion}

To our knowledge, this is the first study investigating the expression of IGFBP7 in AECOPD patients. Serum IGFBP7 levels were found to be significantly raised in patients 
A
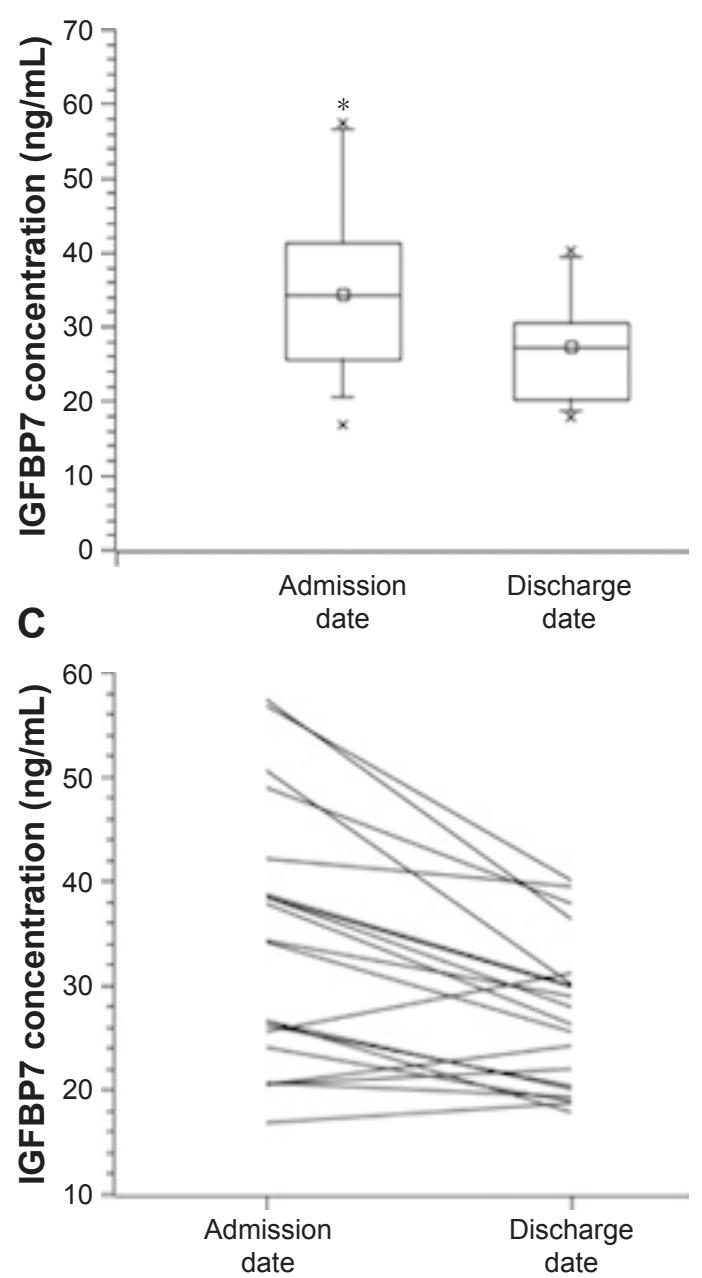

B
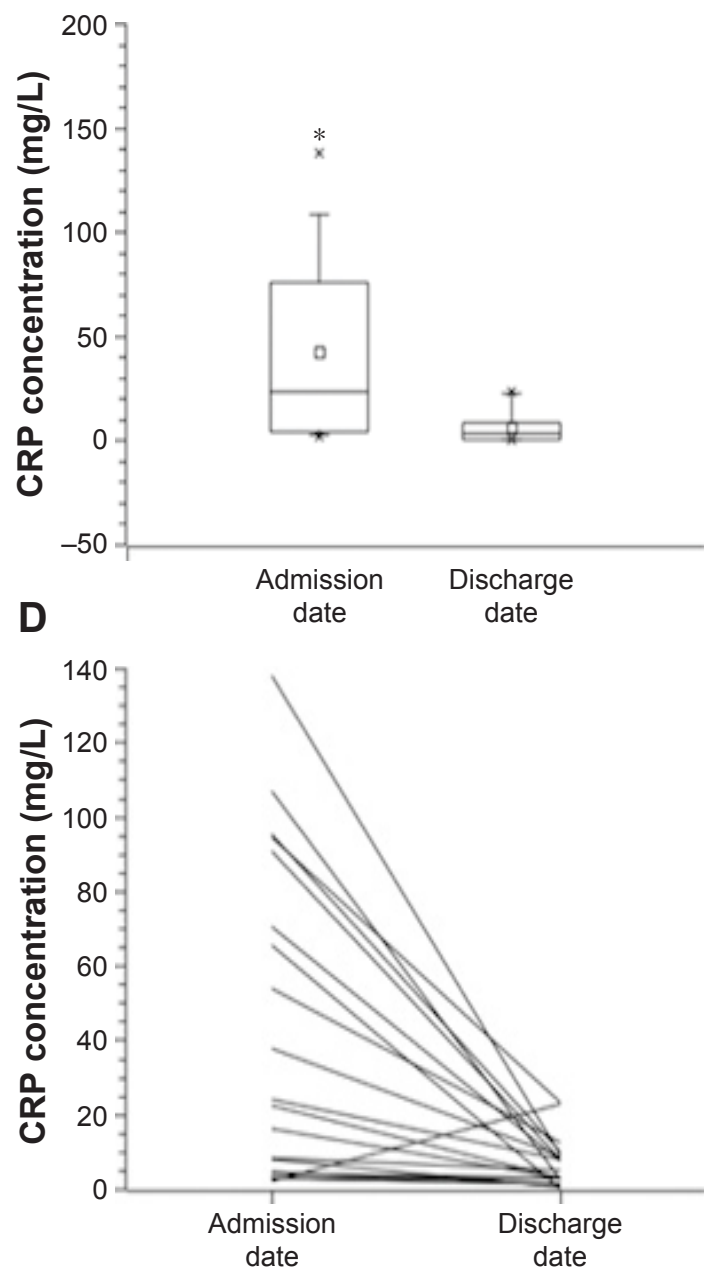

Figure 2 Serum IGFBP7 and CRP concentrations during exacerbations and after clinical improvement in AECOPD patients in the second group.

Notes: (A) Comparison of IGFBP7 level; (B) comparison of CRP level; (C) change of IGFBP7 level during exacerbations and after clinical improvement in 20 AECOPD patients; (D) change of CRP level during exacerbations and after clinical improvement in 20 AECOPD patients.

Abbreviations: AECOPD, acute exacerbation of chronic obstructive pulmonary disease; IGFBP7, insulin-like growth factor binding protein 7; ICU, intensive care unit; CRP, C-reactive protein.

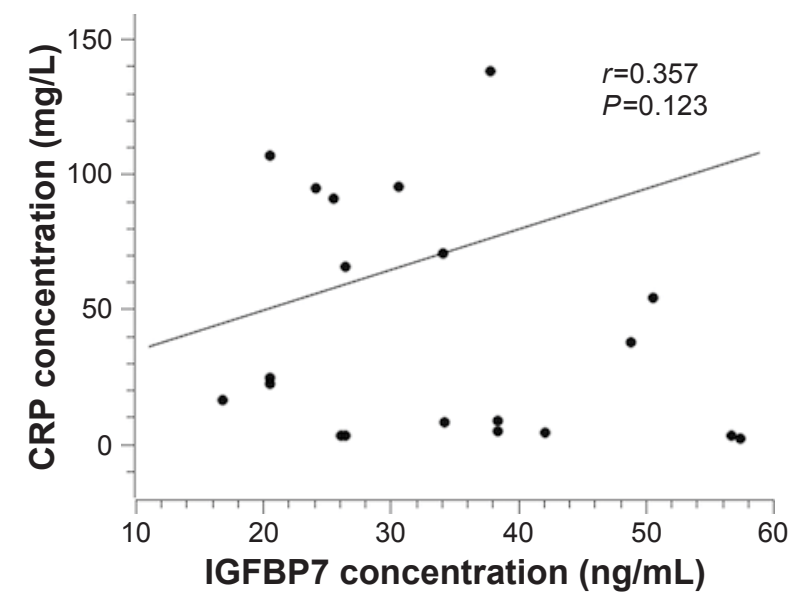

Figure 3 Correlation of serum IGFBP7 levels with CRP levels in patients with COPD exacerbations in the second group.

Notes: Spearman analysis was performed. $r=0.357, P=0.123$.

Abbreviations: IGFBP7, insulin-like growth factor binding protein 7; CRP, C-reactive protein; COPD, chronic obstructive pulmonary disease. suffering from AE compared to healthy subjects. To reduce the potential bias, we verified the results in another population of hospitalized AECOPD patients. In the second group of AECOPD subjects, the increased IGFBP7 levels reduced after recovery.

A comprehensive approach to biomarkers could potentially revolutionize the diagnosis and management of AECOPD. The increased level of serum biomarkers during AE could help clinicians to identify AECOPD early in the clinical course to enable intervention. In recent years, biomarker candidates have been reported for AECOPD. ${ }^{16-19}$ Chen et al conducted a systematic review. CRP, interleukin-6, and tumor necrosis factor-alpha were the most frequently studied biomarkers. Compared to convalescence, only CRP levels were found to be consistently increased during AE. ${ }^{16}$ The increase in CRP during AECOPD and 


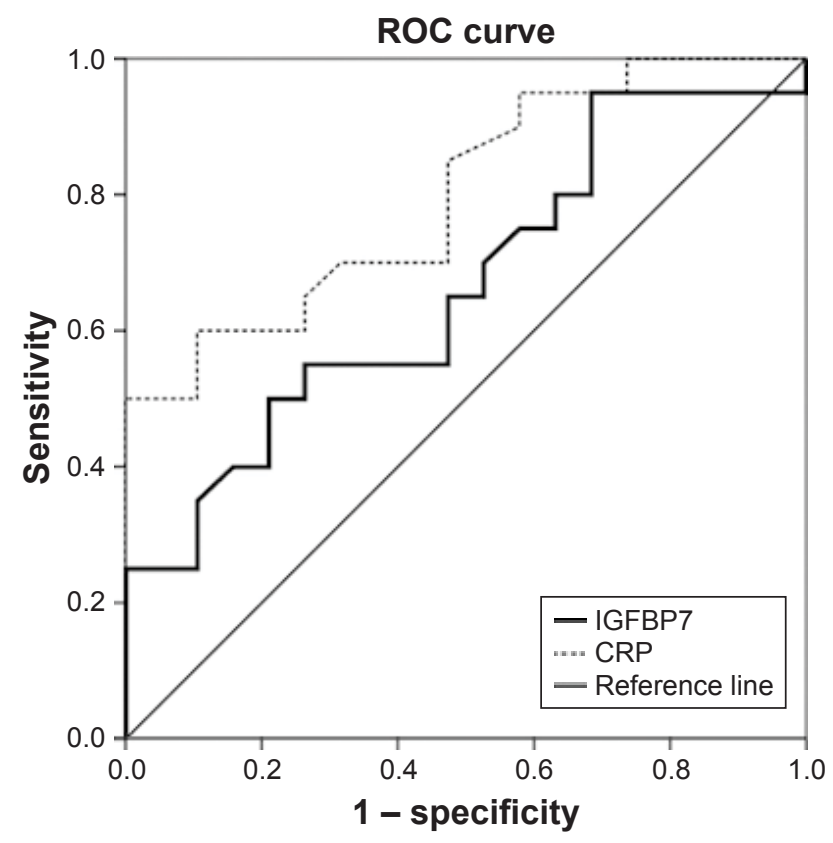

Figure 4 ROC curve for IGFBP7 and CRP in discrimination of AECOPD patients on the admission day and discharge day in the second group.

Abbreviations: IGFBP7, insulin-like growth factor binding protein 7; CRP, C-reactive protein; AECOPD, acute exacerbation of chronic obstructive pulmonary disease; ROC, receiver operating characteristic.

decrease at recovery was confirmed in our study. As in the CRP expression pattern, IGFBP7 concentrations also appeared to be raised during AE compared with recovery, suggesting that IGFBP7 might be a biomarker candidate of AECOPD and a biomarker candidate in the assessment of treatment response.

We then analyzed the relation between IGFBP7 expression and CRP expression during AE of COPD. However, unexpectedly, we were unable to detect any significant linear correlation between IGFBP7 and CRP $(r=0.357$, $P=0.123)$. We hypothesized that there must be some difference between IGFBP7 and CRP, although they both increased during AE. Although the ROC analysis showed that the diagnostic value of IGFBP7 in AECOPD is weaker than CRP, IGFBP7 probably has its own value in the diagnosis of AECOPD. COPD exacerbations are heterogeneous in etiology, and are almost clinically indistinguishable. Bafadhel et al identified distinct subtypes in AECOPD. ${ }^{20}$ The subtypes related to bacterial infection, viral infection, and increased eosinophil counts were $~ 55 \%, 29 \%$, and 28\%, respectively. ${ }^{20}$ Management of AECOPD should depend on the different phenotype. ${ }^{21}$ Serum biomarkers capable of identifying different AECOPD phenotypes should guide suitable treatment. Bacterial infection is the main cause for AECOPD. ${ }^{22} \mathrm{CRP}$ is a potentially useful biomarker indicating bacterial infection. The raised CRP in AECOPD may suggest benefit from antibiotic therapy. ${ }^{23}$ In our study, CRP increased in most AECOPD cases. However for some of the hospitalized AECOPD patients, the CRP levels were almost normal. This phenomenon may be due to viral infection or environmental factors which can also lead to AE. While for these AECOPD patients with normal CRP level, the expression of IGFBP7 increased. ${ }^{20-24}$

Our study suggests that IGFBP7 expression in patients in ICU needing assistant ventilation was higher than in the patients not in ICU, although the difference was not statistically significant. In the ICU group, one patient, with the highest IGFBP7 expression during AE $(81.2 \mathrm{ng} / \mathrm{mL})$, died within 3 days. We wanted to clarify whether the increase in IGFBP7 was due to the severe bacterial infection. Circulating PCT levels are raised in severe bacterial infections, but not in viral infections or in non-specific inflammatory diseases. ${ }^{24} \mathrm{We}$ explored the relationship between IGFBP7 and PCT. As a result, almost no correlation between the two molecules was found ( $r=0.178$, data not shown). We believe that the serum IGFBP7 level during AE of COPD should not be used to indicate severe bacterial infection. We hypothesized that the level of serum IGFBP7 was probably an indication of airway inflammation during AE. The role of IGFBP7 in airway inflammation and airway remodeling needs further exploration. Further study is needed to explore the value of IGFBP7 to distinguish AECOPD phenotypes.

In conclusion, the present study provides the first evidence that serum IGFBP7 levels are raised during AE of COPD. After convalescence, the levels reduced, suggesting that IGFBP7 might be a biomarker candidate of AECOPD and a biomarker candidate in the assessment of treatment response. However, no significant linear correlation between IGFBP7 and CRP was found. There is a considerable need to explore the value of IGFBP7 in differentiating AECOPD phenotypes, while the detailed mechanism of IGFBP7 in airway inflammation and airway remodeling awaits further study.

\section{Acknowledgments}

This work was supported by the Zhejiang Provincial Natural Science Foundation of China (LY17H160007). We thank Dr Brian Eyden (Manchester, UK) for assistance with English language expression.

\section{Author contributions}

WR designed the experiments, collected the clinical data, and drafted the manuscript; MW analyzed the data; FL, LS, and LD collected the serum samples; YQ and XW collected the clinical data; KY conceived and designed the experiments. 
All authors contributed toward data analysis, drafting and revising the paper and agree to be accountable for all aspects of the work.

\section{Disclosure}

The authors report no conflicts of interest in this work.

\section{References}

1. Celli BR, Barnes PJ. Exacerbations of chronic obstructive pulmonary disease. Eur Respir J. 2007;29(6):1224-1238.

2. Rodriguez-Roisin R. Toward a consensus definition for COPD exacerbations. Chest. 2000;117(5 Suppl 2):398S-401S.

3. Rabe KF, Hurd S, Anzueto A, et al. Global strategy for the diagnosis, management, and prevention of chronic obstructive pulmonary disease: GOLD executive summary. Am J Respir Crit Care Med. 2007; 176(6):532-555.

4. Tuder RM, Petrache I. Pathogenesis of chronic obstructive pulmonary disease. J Clin Invest. 2012;122(8):2749-2755.

5. Creutzberg EC, Wouters EF, Vanderhoven-Augustin IM, Dentener MA, Schols AM. Disturbances in leptin metabolism are related to energy imbalance during acute exacerbations of chronic obstructive pulmonary disease. Am J Respir Crit Care Med. 2000;162(4 Pt 1):1239-1245.

6. Dentener MA, Creutzberg EC, Schols AM, et al. Systemic anti-inflammatory mediators in COPD: increase in soluble interleukin 1 receptor II during treatment of exacerbations. Thorax. 2001;56(9): $721-726$.

7. Yoon HI, Sin DD. Biomarkers of therapeutic response in patients with chronic obstructive pulmonary disease: a critical review of the literature. Drugs. 2011;71(14):1821-1837.

8. Lee H, Kim SR, Oh Y, Cho SH, Schleimer RP, Lee YC. Targeting insulin-like growth factor-I and insulin-like growth factor-binding protein-3 signaling pathways. A novel therapeutic approach for asthma. Am J Respir Cell Mol Biol. 2014;50(4):667-677.

9. Yamanaka Y, Wilson EM, Rosenfeld RG, Oh Y. Inhibition of insulin receptor activation by insulin-like growth factor binding proteins. $J$ Biol Chem. 1997;272(49):30729-30734.

10. Wilson HM, Birnbaum RS, Poot M, Quinn LS, Swisshelm K. Insulinlike growth factor binding protein-related protein 1 inhibits proliferation of MCF-7 breast cancer cells via a senescence-like mechanism. Cell Growth Differ. 2002;13(5):205-213.

11. Allen JT, Bloor CA, Kedia RK, Knight RA, Spiteri MA. Expression of growth hormone-releasing factor, growth hormone, insulin-like growth factor-1 and its binding proteins in human lung. Neuropeptides. 2000; 34(2):98-107.
12. Muller KC, Welker L, Paasch K, et al. Lung fibroblasts from patients with emphysema show markers of senescence in vitro. Respir Res. 2006; $7: 32$.

13. Starkey MR, Jarnicki AG, Essilfie AT, et al. Murine models of infectious exacerbations of airway inflammation. Curr Opin Pharmacol. 2013; 13(3):337-344.

14. Vestbo J, Hurd SS, Agusti AG, et al. Global strategy for the diagnosis, management, and prevention of chronic obstructive pulmonary disease: GOLD executive summary. Am J Respir Crit Care Med. 2013; 187(4):347-365.

15. Liu Y, Wu M, Ling J, et al. Serum IGFBP7 levels associate with insulin resistance and the risk of metabolic syndrome in a Chinese population. Sci Rep. 2015;5:10227.

16. Chen YW, Leung JM, Sin DD. A Systematic review of diagnostic biomarkers of COPD exacerbation. PLoS One. 2016;11(7):e0158843.

17. Cho YJ, Ma JE, Yun EY, et al. Serum angiopoietin-2 levels are elevated during acute exacerbations of COPD. Respirology. 2011; 16(2):284-290.

18. Bozinovski S, Hutchinson A, Thompson M, et al. Serum amyloid a is a biomarker of acute exacerbations of chronic obstructive pulmonary disease. Am J Respir Crit Care Med. 2008;177(3):269-278.

19. Leung JM, Chen V, Hollander Z, et al. COPD exacerbation biomarkers validated using multiple reaction monitoring mass spectrometry. PLoS One. 2016;11(8): 0161129.

20. Bafadhel M, McKenna S, Terry S, et al. Acute exacerbations of chronic obstructive pulmonary disease: identification of biologic clusters and their biomarkers. Am J Respir Crit Care Med. 2011;184(6):662-671.

21. Bafadhel M, McKenna S, Terry S, et al. Blood eosinophils to direct corticosteroid treatment of exacerbations of chronic obstructive pulmonary disease: a randomized placebo-controlled trial. Am J Respir Crit Care Med. 2012;186(1):48-55.

22. Sethi S, Murphy TF. Infection in the pathogenesis and course of chronic obstructive pulmonary disease. N Engl J Med. 2008;359(22): 2355-2365.

23. Daniels JM, Schoorl M, Snijders D, et al. Procalcitonin vs C-reactive protein as predictive markers of response to antibiotic therapy in acute exacerbations of COPD. Chest. 2010;138(5):1108-1115.

24. Assicot M, Gendrel D, Carsin H, Raymond J, Guilbaud J, Bohuon C. High serum procalcitonin concentrations in patients with sepsis and infection. Lancet. 1993;341(8844):515-518.
International Journal of COPD

\section{Publish your work in this journal}

The International Journal of COPD is an international, peer-reviewed journal of therapeutics and pharmacology focusing on concise rapid reporting of clinical studies and reviews in COPD. Special focus is given to the pathophysiological processes underlying the disease, intervention programs, patient focused education, and self management protocols.

\section{Dovepress}

This journal is indexed on PubMed Central, MedLine and CAS. The manuscript management system is completely online and includes a very quick and fair peer-review system, which is all easy to use. Visit $\mathrm{http}: / / \mathrm{www}$.dovepress.com/testimonials.php to read real quotes from published authors. 